\title{
Epidemiology of Enuresis among Children in Diyala Governorate
}

Enas S Salahaldeen $(\mathrm{MBChB})^{1}$, Nadhim Gh Noaman $(\mathrm{PhD})^{2}$ and Mehdi SH Al-Zuheiry $(\mathrm{PhD})^{3}$

\footnotetext{
${ }^{1}$ College of Medicine, Diyala University, Diyala ,Iraq

${ }^{2}$ College of Medicine, Diyala University, Diyala ,Iraq

${ }^{3}$ College of Medicine, Diyala University, Diyala ,Iraq

Correspondence Address:

Enas S Salahaldeen

College of Medicine, Diyala University, Diyala ,Iraq

email: enassaleh984@gmail.com
}

Received: 15 November 2020

Revised: 30 November 2020

Accepted: 6 December 2020

Published: 25 June 2021

Diyala Medical Journal 2021:20(2): 31- 42

\begin{abstract}
Background: Nocturnal enuresis, is intermittent involuntary voiding in a child aged five years or more. One time a month for three months is required for the diagnosis. It is a common problem in children. It is the cause of stress for them and for their families. Enuresis can be classified into two types to understand its causes and treatment. These types are primary and secondary enuresis, monosymptomatic and polysymptomatic. Primary enuresis always associated with a familial history of delayed control of the urinary bladder. Secondary enuresis may cause by urinary tract or neurogenic causes like the spinal cord and urinary tract infection. Most of the cases were of the primary type.

Objective: To evaluate the associated factor of nocturnal enuresis, study the various types of nocturnal enuresis, and evaluate the associated factors that affect the types of nocturnal enuresis.

Patients and Methods: A cross-sectional study conducted in outpatient clinic of Albatool hospital in Diyala province, Iraq, 150 children was eligible in the study, which started from $1^{\text {st }}$ Febreuary to $30^{\text {th }}$ June 2020 . Collection of the data was done by interview parents' or the children's caregiver by a questionnaire that was used before for study enuresis. Analysis was carried out using statistical package for social sciences SPSS version 24.

Results: The present study included 150 patients with enuresis, their mean age was $7.51 \pm 1.34$ years (range: $=5-10$ years), there were $(59.3 \%)$ males and $(40.7 \%)$ females. Most of the patients (61.3\%) had 2-3 sibling, second in their birth order (52\%), reside in the urban area (56\%), a majority of the mothers $38 \%$ had primary school as their highest educational attainment, a
\end{abstract}


majority of the fathers $(32.7 \%)$ had secondary school as their highest educational attainment, most of the mothers $62.7 \%$ were housewives and $57.3 \%$ of fathers were employees. Regarding clinical features of the patients, $32 \%$ had a family history of enuresis, $52 \%$ had a history of fluid consumption other than water, $7.3 \%$ had a history of punishment, $8 \%$ had history of constipation, $27.3 \%$ had a history of emotional stress, $5.3 \%$ had a history of DM, 30.7\% had a history of drug intake, $61.3 \%$ reveal UTI in their urinalysis, $78 \%$ reveal abnormal US findings. Secondary enuresis was found in $65.3 \%$ of the patients, while primary enuresis found in $34.7 \%$ of the patients, $7.3 \%$ of the patients complaining of diurnal enuresis. All studied factors not significantly associated with types of enuresis except constipation was found more in patients with secondary enuresis $91.7 \%$.

Conclusion: According to the previous study many risk factors were associated with nocturnal enuresis, in the current study these risk factors, except constipation which was associated with secondary enuresis, were not associated with nocturnal enuresis.

Keywords: Enuresis; Nocturnal; Diurnal; primary; Secondary; Constipation

\section{Introduction}

Enuresis is intermittent involuntary voiding during sleep in a child aged five years and more. One episode per month for three months is required for the diagnosis [1].

Enuresis is a common problem in children. It is a source of stress for them, as well as for their families, who may also incur significant financial costs [2].

The prevalence of nocturnal enuresis is $16.1 \%$ at age of five years and $10.1 \%$ at 7 years, then decreases with increasing age. The etiology may include nocturnal polyuria, small functional bladder capacity, an arousal problem, or a mixture of these [3, 4].

Enuresis results from the interplay of three physiological factors: defective sleep arousal; nocturnal polyuria; and bladder factors, such as lack of inhibition of bladder emptying during sleep, reduced bladder capacity, or bladder over activity [1]. Enuresis can be classified in two ways to better understand its causes and how to treat the patient. These types are primary and secondary, monosymptomatic, and polysymptomatic.
Primary nocturnal enuresis means the child never had a period of nighttime dryness that lasts longer than six months and this classification accounts for roughly $80 \%$ of cases. Primary enuresis is often associated with a familial history of delayed urinary bladder control. Ninety percent of enuresis cases are primary, and its prevalence usually changes with age (5).

Urologic and neurological problems, disorders of the spinal cord, and recurrent urinary tract infection can constitute the causes of Secondary enuresis [5].

Eighty to $90 \%$ of enuresis cases are identified as primary enuresis and are based on genetic predisposition, biological and developmental factors. On the other hand, secondary enuresis frequently arises from psychological factors [6].Enuresis is multifactorial with a genetic cause [7].

The conditions that coexisted with enuresis include constipation, cystitis, diabetes insipidus, disorders of sleep arousal, urethral 
obstruction, ectopic ureter, small bladder capacity, overactive bladder [8].

Two first-line treatment options of nocturnal enuresis are currently recommended: non pharmacologic treatment and pharmacologic treatment [9].

Motivational therapy differs for each patient; it is a style of therapeutic intervention that can be given as treatment together with pharmacological therapy [10].

The choice of treatment depends on the frequency and severity of symptoms, the child's age and motivation. Treatment options for nocturnal enuresis are the use of desmopressin, alarm devices, and imipramine. In particular, the main therapeutic effect of desmopressin is its antidiuretic activity. Desmopressin rapidly reduces the number of wet nights per week compared with placebo and with homotoxicological remedies [10].

Enuresis can cause embarrassment, loss of self-esteem social isolation. The significant negative effect of enuresis on the child leads to best diagnosed and managed by inter professional team. Pharmacists can deal with the dose and counsel on proper administration. the healthcare team can concern in these areas that require communication. Only through this type of inter professional cooperation can achieve optimal potential patient outcomes [11].

This study aimed to evaluate the associated factor of nocturnal enuresis, study the various types of nocturnal enuresis, and evaluate the associated factors that affect the types of nocturnal enuresis.

\section{Patients and Methods}

A cross-sectional study conducted in the pediatric department in Albatool hospital in
Diyala province, Iraq. The target population was the children attending the outpatient clinic of the pediatric department in Albatool hospital in Diyala province, Iraq. about 150 children were eligible for the study which started from $1^{\text {st }}$ of February to $30^{\text {th }}$ June 2020. All children complaining of enuresis included in the study.

Data collection was done through direct interviews of the parents' or guardians of the children using a questionnaire that was used before for study enuresis. The questionnaire was in an Arabic language and the English copy. To minimize any embarrassment to the children, parents or guardians were accessed directly to obtain the information.

The first part of the questionnaire included social features of the patients (age, sex, residence, numbers of siblings, child order), second part asked about types of enuresis and its characteristics: Patients factors, parent factors, clinical and laboratory factors of the patients. All patients send for general urine analysis and abdominal ultrasound. UTI based on clinical findings (polyuria, dysuria, urgency, hematuria) and positive urinalysis (pyuria=urine leukocyte, $>5$ to 6 per highpower field). A signed informed written consent from (parents/guardians) to participate in the study and they were informed that their identity will not be revealed and the work is done for research purpose.

\section{Statistical analysis}

Statistical analysis was done using a statistical package for social sciences SPSS version 24 and Excel Microsoft office 2010. The data presented as frequency and percentage tables, pie and bar charts were used also, chi-square test of significance of 
association was performed to assess relations between categorical variables, independent $t$ test was used to test the mean difference of continuous variables, statistically significant was a p-value less than 0.05 .

\section{Results}

The present study included 150 patients with enuresis, their mean age was $7.51 \pm 1.34$ years (range: $=5-10$ years), $59.3 \%$ of them were males and $40.7 \%$ females. Of the total patients, $1.3 \%$ of the patient had one sibling and $61.3 \%, 37.3 \%$ of the patients had $2-3$ and $>3$ siblings respectively. $(6 \%)$ of the patients were the first born child, 52\%, 38.7\%, 3.3\% of the patients were born in $2^{\text {nd }}, 3^{\text {rd }}, 4^{\text {th }}$ order respectively. $56 \%$ of the patients were residing in the urban areas, $44 \%$ of the patients residence in rural areas. A majority of the mothers $(38 \%)$ had primary school as their highest educational attainment while $(30.7 \%)$ of the mothers were illiterate and $(30 \%),(1.3 \%)$ of the mothers had secondary and higher education achievement respectively. The majority of the fathers

Table (1): Relationship between patients' sociodemographic factors and type of enuresis (according to the onset of enuresis)

\begin{tabular}{|c|c|c|c|c|}
\hline \multicolumn{2}{|c|}{ Sociodemographic factors } & \multicolumn{2}{|l|}{ Type of enuresis } & \multirow[t]{2}{*}{ P value } \\
\hline & & Primary & Secondary & \\
\hline \multirow[t]{2}{*}{ Sex } & Male & $35(39.3 \%)$ & $54(60.7 \%)$ & \multirow[t]{2}{*}{0.1} \\
\hline & Female & $17(27.9 \%)$ & $44(72.1 \%)$ & \\
\hline \multirow[t]{3}{*}{ Number of sibling } & 1 & $1(50 \%)$ & $1(50 \%)$ & \multirow{3}{*}{1} \\
\hline & $2-3$ & $32(34.8 \%)$ & $60(65.2 \%)$ & \\
\hline & $>3$ & $19(33.9 \%)$ & $37(66.1 \%)$ & \\
\hline \multirow[t]{4}{*}{ Child order } & $1^{\mathrm{st}}$ & $3(33.3 \%)$ & $6(66.7 \%)$ & \multirow{4}{*}{0.4} \\
\hline & $2^{\text {nd }}$ & $28(35.9 \%)$ & $50(64.1 \%)$ & \\
\hline & $3^{\text {rd }}$ & $21(36.2 \%)$ & $37(63.8 \%)$ & \\
\hline & $4^{\text {th }}$ & $0(0 \%)$ & $5(100 \%)$ & \\
\hline \multirow[t]{2}{*}{ Residence } & Urban & $32(38.1 \%)$ & $52(61.9 \%)$ & \multirow[b]{2}{*}{0.3} \\
\hline & Rural & $20(30.3 \%)$ & $46(69.7 \%)$ & \\
\hline
\end{tabular}

*Chi-square test highest educational attainment while $(30.7 \%)$ of the fathers had primary and $(24.7 \%)$ of the fathers were illiterate, $(12 \%)$ of the fathers had higher education achievement. There were $(62.7 \%)$ patients whom mothers were housewives, (37.3\%) mothers were employees. There were $(57.3 \%)$ patients whom fathers were free workers, $(42.7 \%)$ fathers were employees. Secondary enuresis was found in $(65.3 \%)$ patients, while primary enuresis found in (34.7\%) patients, (7.3\%) patients complaining of diurnal enuresis.

Regarding the types of enuresis according to the onset of enuresis, there was no significant mean age difference between patients who had primary enuresis and those who had secondary enuresis. There was no association between patients' sociodemographic factors and type of enuresis Table(1). 
There was no significant association between enuresis Table (2).

parents' education or occupation and type of

Table (2): Relationship between parents' factors and type of enuresis (according to the onset of enuresis)

\begin{tabular}{|c|c|c|c|c|}
\hline \multicolumn{2}{|l|}{ parents' factors } & \multicolumn{2}{|c|}{ Types of enuresis } & \multirow{2}{*}{$\begin{array}{r}\text { P value } \\
0.3\end{array}$} \\
\hline Mother education & illiterate & $\begin{array}{l}\text { Primary } \\
20(43.5 \%)\end{array}$ & $\begin{array}{r}\text { Secondary } \\
26(56.5 \%)\end{array}$ & \\
\hline & primary & $18(31.6 \%)$ & $39(68.4 \%)$ & \\
\hline & secondary & $14(31.1 \%)$ & $31(68.9 \%)$ & \\
\hline & higher education & $0(0 \%)$ & $2(100 \%)$ & \\
\hline \multirow{4}{*}{ Father education } & illiterate & $15(40.5 \%)$ & $22(59.5 \%)$ & \multirow{4}{*}{0.7} \\
\hline & primary & $15(32.6 \%)$ & $31(67.4 \%)$ & \\
\hline & secondary & $17(34.7 \%)$ & $32(65.3 \%)$ & \\
\hline & higher education & $5(27.8 \%)$ & $13(72.2 \%)$ & \\
\hline \multirow[b]{2}{*}{ Mother occupation } & Housewife & $32(34.0 \%)$ & $62(66.0 \%)$ & \multirow[b]{2}{*}{0.8} \\
\hline & Employee & $20(35.7 \%)$ & $36(64.3 \%)$ & \\
\hline \multirow[b]{2}{*}{ Father occupation } & Free workers & $30(34.9 \%)$ & $56(65.1 \%)$ & \multirow[b]{2}{*}{0.9} \\
\hline & Employee & $22(34.4 \%)$ & $42(65.6 \%)$ & \\
\hline
\end{tabular}

* Chi-square test

Constipation was found more in patients with between other patients' clinical features or secondary enuresis $(91.7 \%)$ and this association was statistically significant, clinical history and type of enuresis Table $\mathrm{p}=0.003$, there was no significant association

Table (3): Relationship between patients' clinical factors and type of enuresis (according to the onset of enuresis)

\begin{tabular}{|c|c|c|c|c|}
\hline \multicolumn{2}{|c|}{ clinical factors } & \multicolumn{2}{|c|}{ Types of enuresis } & \multirow[t]{2}{*}{$P$ value } \\
\hline & & Primary & Secondary & \\
\hline \multirow[t]{2}{*}{ Family history of enuresis } & Yes & $20(41.7 \%)$ & $28(58.3 \%)$ & \multirow[t]{2}{*}{0.1} \\
\hline & No & $32(31.4 \%)$ & $70(68.6 \%)$ & \\
\hline \multirow[b]{2}{*}{ history of fluid consumption } & YYes & $29(37.2 \%)$ & $499(62.8 \%)$ & 0.6 \\
\hline & No & $23(31.9 \%)$ & $49(68.1 \%)$ & \\
\hline \multirow[t]{2}{*}{ history of punishment } & YYes & $4(36.4 \%)$ & $7(63.6 \%)$ & \multirow[t]{2}{*}{0.5} \\
\hline & No & $48(34.5 \%)$ & $91(65.5 \%)$ & \\
\hline \multirow[t]{2}{*}{ History of constipation } & Yes & $1(8.3 \%)$ & $11(91.7 \%)$ & \multirow[t]{2}{*}{$0.003^{*}$} \\
\hline & No & $51(37.0 \%)$ & $87(63.0 \%)$ & \\
\hline \multirow[t]{2}{*}{ History of emotional stress } & Yes & $10(24.4 \%)$ & $31(75.6 \%)$ & \multirow[b]{2}{*}{0.1} \\
\hline & No & $42(38.5 \%)$ & $67(61.5 \%)$ & \\
\hline \multirow[t]{2}{*}{ Presence of UTI } & Yes & $20(34.5 \%)$ & $38(65.5 \%)$ & \multirow[b]{2}{*}{0.9} \\
\hline & No & $32(34.8 \%)$ & $60(65.2 \%)$ & \\
\hline \multirow[t]{2}{*}{ History of DM } & Yes & $2(25.0 \%)$ & $6(75.0 \%)$ & \multirow{2}{*}{$\frac{0.9}{0.7}$} \\
\hline & No & $50(35.2 \%)$ & $92(64.8 \%)$ & \\
\hline \multirow[t]{2}{*}{ History of drug intake } & Yes & $12(26.1 \%)$ & $34(73.9 \%)$ & \multirow[t]{2}{*}{0.09} \\
\hline & No & $40(38.5 \%)$ & $98(65.3 \%)$ & \\
\hline \multirow[t]{2}{*}{ US findings } & Positive & $40(34.2 \%)$ & $77(65.8 \%)$ & \multirow[t]{2}{*}{0.8} \\
\hline & Negative & $12(36.4 \%)$ & $77(65.8 \%)$ & \\
\hline
\end{tabular}


Regarding the type of enuresis according to the day-time classification, there was no significant mean age difference between patients who had nocturnal enuresis and those who had diurnal enuresis. There was no association

between sactors and type of enuresis according to the day time of enuresis Table (4).

Table (4): Relationship between patients' sociodemographic factors and type of enuresis (according to the day time of enuresis)

\begin{tabular}{|c|c|c|c|c|}
\hline \multicolumn{2}{|c|}{ Sociodemographic factors } & \multicolumn{2}{|c|}{ Type of enuresis } & \multirow[t]{2}{*}{ P value } \\
\hline & & Nocturnal & Diurnal & \\
\hline \multirow[t]{2}{*}{ Sex } & Male & $83(93.3 \%)$ & $6(6.7 \%)$ & \multirow[t]{2}{*}{0.7} \\
\hline & Female & $56(91.8 \%)$ & $5(8.2 \%)$ & \\
\hline \multirow[t]{3}{*}{ Number of sibling } & 1 & $1(50 \%)$ & $1(50 \%)$ & \multirow[t]{3}{*}{0.1} \\
\hline & $2-3$ & $86(93.5 \%)$ & $6(6.5 \%)$ & \\
\hline & $>3$ & $52(92.9 \%)$ & $4(7.1 \%)$ & \\
\hline \multirow{4}{*}{ Child order } & $1^{\mathrm{st}}$ & $8(88.9 \%)$ & $1(11.1 \%)$ & \multirow{4}{*}{0.8} \\
\hline & $2^{\text {nd }}$ & $72(92.3 \%)$ & $6(7.7 \%)$ & \\
\hline & $3^{\text {rd }}$ & $54(93.1 \%)$ & $4(6.9 \%)$ & \\
\hline & $4^{\text {th }}$ & $5(100 \%)$ & $0(0 \%)$ & \\
\hline \multirow[t]{2}{*}{ Residence } & Urban & $76(90.5 \%)$ & $8(9.5 \%)$ & \multirow[t]{2}{*}{0.1} \\
\hline & Rural & $63(95.5 \%)$ & $3(4.5 \%)$ & \\
\hline
\end{tabular}

There was no significant association type of enuresis Table (5). between parents' education or occupation and

Table (5): Relationship between parents' factors and type of enuresis (according to the day time of enuresis)

\begin{tabular}{|c|c|c|c|c|}
\hline \multirow{2}{*}{\multicolumn{2}{|c|}{ parents' factors }} & \multicolumn{2}{|c|}{ Types of enuresis } & \multirow[t]{2}{*}{ P value } \\
\hline & & Nocturnal & Diurnal & \\
\hline \multirow[t]{4}{*}{ Mother education } & illiterate & $43(93.5 \%)$ & $3(6.5 \%)$ & \multirow[t]{4}{*}{0.6} \\
\hline & primary & $54(94.7 \%)$ & $3(5.3 \%)$ & \\
\hline & secondary & 40(88.9\%) & $5(11.1 \%)$ & \\
\hline & higher education & $2(100 \%)$ & $0(0 \%)$ & \\
\hline \multirow{4}{*}{ Father education } & illiterate & $37(100.0 \%)$ & $0(0 \%)$ & \multirow{4}{*}{0.07} \\
\hline & primary & 43(93.5\%) & $3(6.5 \%)$ & \\
\hline & secondary & $42(85.7 \%)$ & $7(14.3 \%)$ & \\
\hline & higher education & $17(94.4 \%)$ & 1)5.6\%) & \\
\hline \multirow[t]{2}{*}{ Mother occupation } & "Housewife & $87(92.6 \%)$ & $7(7.4 \%)$ & \multirow[t]{2}{*}{0.6} \\
\hline & Employee & $352(92.9 \%)$ & 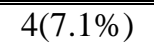 & \\
\hline \multirow[t]{2}{*}{ Father occupation } & Free workers & $80(93.0 \%)$ & $6(7.0 \%)$ & \multirow[t]{2}{*}{0.6} \\
\hline & Employee & $59(92.2 \%)$ & $5(7.8 \%)$ & \\
\hline
\end{tabular}

*Chi-square test

There was no significant association between history and type of enuresis Table (6). other patients' clinical features or clinical 
Table (6): Relationship between patients' clinical factors and type of enuresis (according to the onset of enuresis)

\begin{tabular}{|c|c|c|c|c|}
\hline \multirow{2}{*}{\multicolumn{2}{|c|}{ clinical factors }} & \multicolumn{2}{|c|}{ Types of enuresis } & \multirow[t]{2}{*}{ P value } \\
\hline & & Nocturnal & Diurnal & \\
\hline \multirow[t]{2}{*}{ Family history of enuresis } & Yes & $44(91.7 \%$ & $4(8.3 \%$ & \multirow[t]{2}{*}{0.7} \\
\hline & No & 95(93.1\% & $7(6.9 \%$ & \\
\hline \multirow[b]{2}{*}{ history of fluid consumption } & Yes & $72(92.3 \%$ & $6(7.7 \%$ & \multirow[b]{2}{*}{0.8} \\
\hline & No & $67(93.1 \%$ & $5(6.9 \%$ & \\
\hline \multirow[t]{2}{*}{ history of punishment } & Yes & $11(100.0 \%$ & $0(0 \%$ & \multirow[t]{2}{*}{0.4} \\
\hline & No & $128(92.1 \%$ & $11(7.9 \%$ & \\
\hline \multirow[t]{2}{*}{ History of constipation } & Yes & $12(100.0 \%$ & $0(0 \%$ & \multirow[t]{2}{*}{0.6} \\
\hline & No & 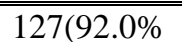 & $=11(8.0 \%$ & \\
\hline \multirow[t]{2}{*}{ History of emotional stress } & Yes & $38(92.7 \%$ & $3(7.3 \%$ & \multirow[t]{2}{*}{0.6} \\
\hline & No & $101(92.7 \%$ & $8(7.3 \%$ & \\
\hline \multirow[t]{2}{*}{ History of UTI } & Yes & $51(87.9 \%$ & $7(12.1 \%$ & \multirow[t]{2}{*}{0.07} \\
\hline & No & $88(95.7 \%$ & $4(4.3 \%$ & \\
\hline \multirow[t]{2}{*}{ History of DM } & Yes & $7(87.5 \%$ & $1(12.5 \%$ & \multirow[t]{2}{*}{0.4} \\
\hline & No & $132(93.0 \%$ & $10(7.0 \%$ & \\
\hline \multirow[t]{2}{*}{ History of drug intake } & Yes & $41(89.1 \%$ & $5(10.9 \%$ & \multirow[t]{2}{*}{0.2} \\
\hline & No & $98(94.2 \%$ & $6(5.8 \%$ & \\
\hline
\end{tabular}

\section{Discussion}

In general, the prevalence of nocturnal enuresis decreases with increasing age. The traditional concept is that most cases are caused by a developmental immaturity of voiding control. Hence many parents and medical practitioners have adopted an expectant or observational approach, assuming that the problem is harmless and will mostly spontaneously resolve as the child ages [12].

Although there were many studies about enuresis, the primary and secondary enuresis not studied in detail. The present study found that the percentage of enuresis was $59.3 \%$ in male and $40.7 \%$ in female, that is mean male predominance, similarly Ali, (2012) found that the prevalence of enuresis in boys and girls were $24.6 \%$ and $19.5 \%$ respectively [13] and Saleh and Al-saffar (2015) also found that enuresis found in males were more than females $(60.3 \%$ versus $39.7 \%)$ [14]. While Sarici (2016) demonstrated that the prevalence of NE among boys and girls was $12.4 \%$ and $6.5 \%$, respectively [6].

The present study observed that the prevalence of secondary enuresis was $65.3 \%$, while primary enuresis found in $34.7 \%$ of the patients, Yeung et al (2004) found that the overall prevalence of primary enuresis was 2.3\% [12] because Yeung et al study conducted in adult which means that the primary and overall prevalence of enuresis decreased with increasing age. While, Saleh and Al-Saffar (2015) found that $84.8 \%$ of patients with primary enuresis and $15.2 \%$ had secondary enuresis, which was reverse the current study [14].

The current study observed that the prevalence of diurnal enuresis was $7.3 \%$ and $92.7 \%$ of patients complaining of nocturnal enuresis, current study noticed that the prevalence of diurnal enuresis much less than nocturnal enuresis, this was corresponding to what was found by Ali (2012) who reported that the prevalence of nocturnal enuresis was 
$22 \%$ and diurnal enuresis was $2.5 \%$ [13]. While Yeung (2004) found that $18.4 \%$ of the patients had daytime urinary incontinence [12] and Wen J.G (2006) found that $21.17 \%$ had daytime urinary symptoms [15].

The present study found that there was no sex predominant regarding nocturnal and diurnal enuresis, while Ali (2012) found that nocturnal enuresis was more prevalent in boys, but diurnal enuresis did not reveal a sex bias [13]. Sherah et al (2019) found that the rate of diurnal enuresis was significantly higher in girls $(32.3 \%)$ than in boys $(23.2 \%)$ [16].

The present study found that there was no sex predominant regarding primary and secondary enuresis, Yeung (2004) had similar results [12], while Wen et al (2006) found that primary enuresis was significantly more in boys than in girls [15].

In the present study mean age was not different between patients who had primary and secondary enuresis or those who had nocturnal and diurnal enuresis. While Wen $e t$ al (2009) found that the prevalence of primary enuresis decreased with age [15]. While Sherah et al (2019) found that the primary enuresis was significantly more (53.8\%) among the older age group [17].

The current study found that most of the patients had more than one sibling $(61.3 \%$ of patients had 1-2 sibling ,37.3\% of patients had $>3$ sibling), similarly Ali (2012) found that $47.7 \%$ of the patients had > 1 sibling [13], Saleh and Al-Saffar (2015) found that $52.7 \%$ of the patients had 5-8 siblings [14]. Current study found that there was no significant association between number of sibling that patients had, and whether patients had primary or secondary enuresis, or the patients had nocturnal or diurnal enuresis, while Saleh and Al-Saffar (2015) and Ali (2012) found that enuresis was more in patients who more than one siblings $[13,14]$.

The present study found that most of the patients $(52 \%)$ was $2^{\text {nd }}$ order, Awn et al (2018) found that $60.6 \%$ of the patients were first or second birth order [17], current study found that birth order not significantly associated with primary or secondary enuresis, or nocturnal or diurnal enuresis. Awn et al (2016) found that birth order not significantly associated with nocturnal enuresis [17]. Hassoni et al (2017) demonstrated more nocturnal enuresis was recorded in children who were of $2^{\text {nd }}$ birth order [18].

Current study demonstrated that there were no significant association between enuresis types and children residence, while Gunes A (2009) found that enuresis was significantly more common with village inhabitation than with county inhabitation [19].

A majority of the mothers $38 \%$ had primary school as their highest educational attainment, Ali (2012) found that $88.1 \%$ of the mothers had primary school as their highest educational attainment [13], Saleh and Al-saffar (2015) found that 56.8\% of mothers had primary school attainment. The majority of the fathers $32.7 \%$ [14], in current study, a majority (32.7\%) of the fathers had secondary school as their highest educational attainment, Saleh and Al-saffar (2015) found that $56 \%$ of the fathers had high school or more as their highest educational attainment, Ali (2012) found that $76.8 \%$ of the mothers had primary school as their highest educational attainment, although there was difference in the percentage of parents 
regarding their education but most of them had low educational level [13], current study found that there was no significant association between parents education and whether patients had primary or secondary enuresis, or the patients had nocturnal or diurnal enuresis, also Saleh and Al-saffar (2015) found that there was no significant association between parents education and enuresis [14], while Ali (2012) reported that patients whose parents had low educational level were more prone for enuresis [13].

In this study $37.3 \%$ of mothers were employee while $62.7 \%$ of them were housewives and $57.3 \%$ of fathers were employee while $42.7 \%$ of them were free workers Ali (2012) found that $11.8 \%$ and $91.3 \%$ of the mothers and fathers were employees, respectively [13], Saleh and Alsaffar (2015) found that most of the mothers were housewives $(96.7 \%)$ and most of the fathers were employee (63.4\%) [14], in present study, there was no association between occupation of parents and whether patients had primary or secondary enuresis, or the patients had nocturnal or diurnal enuresis, also Saleh A.A (2015) and Ali A.M (2012) reported same result regarding enuresis $[14,13]$.

In present study $32 \%$ of the patients with enuresis had family history of enuresis, similarly Ali (2012) found that the rate of history of enuresis was $32.7 \%$ [14], while Saleh and Al-Saffar (2015) found that $71.7 \%$ of patients had family history of enuresis [14], Sarici et al (2016) found that 59.2\% had a positive family history of enuresis [6]. Current study found that there was no significant association between family history of enuresis and whether patients had primary or secondary enuresis, or the patients had nocturnal or diurnal enuresis, while Saleh and Al-saffar (2015) and Ali (2012) found that enuresis was more in patients who had family history of enuresis $[13,14]$. Wen J.G (2009) found that $22.87 \%$ of patients with primary nocturnal enuresis had a positive family history significantly associated with primary enuresis [15].

Current study found that $52 \%$ of the patients had history of fluid consumption other than water, while $48 \%$ of the patients reported fluid restriction, Sherah et al (2019) found that fluid restriction was reported by $21.4 \%$ of the patients, the two study had less percentage of fluid restriction [16].

In present study history of punishment was demonstrated in $7.3 \%$, while Sá C.A (2016) found that $85.0 \%$ of the patients had a history of being punished due to enuresis [20].

This study found that history of constipation was found in $8 \%$ of the patients, Sarici $\mathrm{H}$ (2016) reported that constipation was found in $13.2 \%$ of children with enuresis [6].

Current study showed that constipation was found more in patient with secondary enuresis, there was no significant association between history of constipation and whether patients had nocturnal or diurnal enuresis, while Sarici H (2016) found that there was no significant association between enuresis and the presence of constipation [6].

In present study, although most of the patients had history of emotional stress $(72.7 \%)$ there was no significant association between history of emotional stress and whether patients had primary or secondary enuresis, or the patients had nocturnal or diurnal enuresis, similarly Yeung (2004) had same results [12], while Saleh and Al-Saffar 
(2015) found that most of the patients $(63 \%)$ had history of emotional stress and enuresis was associated with emotional stress [14].

Current study found that $38.7 \%$ of the patients with enuresis had history of UTI, similarly Ali (2012) found that the rate of history of UTI was 32.7\% [13], Saleh and AlSaffar (2015) found that $50.5 \%$ of the patients had history of UTI [14], present study found that there was no association between history of UTI and whether patients had primary or secondary enuresis, or the patients had nocturnal or diurnal enuresis, Sherah et al (2019) found that the urinary tract infection did not show significant association with children with nocturnal enuresis [16], while Saleh and Al-Saffar (2015) and Ali (2012) found that enuresis was more in patients who had history of UTI $[14,13]$. present study found that there was no association between history of DM and whether patients had primary or secondary enuresis, or the patients had nocturnal or diurnal enuresis, also Sherah K.M (2019) found that the history of diabetes mellitus did not show significant association with $\mathrm{NE}$ [16].

The present study found that $30.7 \%$ of children received treatment while Ali (2012) showed only $59.5 \%$ of the children were treated by medication [13].

\section{Limitations}

This is a hospital-based study; hence, the findings cannot be generalized to the community level, the research relied on subjective assessments of respondents (parents or children guardian) so recall bias might have introduced. Since the study was cross sectional, the association is not being firmly established.

\section{Conclusions}

Although previous studies have dealt with the nocturnal enuresis in children and its types, they have not studied the associated factors of each type in detail. According to the previous study many risk factors were associated with nocturnal enuresis, in current study these risk factors, except constipation which was associated with secondary enuresis, were not associated with the types of nocturnal enuresis, possibly due to sample size.

Promotion of the school health program in primary health centers, because most of them in preschool and school age, especially psychological aspect of the condition because nocturnal enuresis had a psychological basis.

Educate parents about the prevalence of enuresis and the importance of dealing with the causes and exacerbating factors.

Encourage parents not to punish their children and reduce fluid and beverages, before bedtime. For further research, large population based studies are recommended in order to determine the factors that associated with each type of enuresis.

\section{Recommendations}

For further research, large population based studies are recommended in order to determine the factors that associated with each type of enuresis.

Source of funding: The authors offer all funding research.

Ethical clearance: Data collection, research conduction and statistical analysis done by Dr Enas S. Salahaldeen and Dr. Nadhium G. Nooman.

Conflict of interest: There was no conflict of interest. 


\section{References}

[1]Caldwell P.HY, Deshpande A.V, Gontard A.V, Management of nocturnal enuresis, BMJ; 2013, 347:f6259 doi: 10.1136/bmj.f6259.

[2] O'Flynn N, Nocturnal enuresis in children and young people: NICE clinical guideline, Br J Gen Pract.; 2011, 61(586): 360-362, doi: 10.3399/bjgp11X572562.

[3]Kang B.J, Chung J.M, Lee S.D, Evaluation of Functional Bladder Capacity in Children with Nocturnal Enuresis According to Type and Treatment Outcome, Res Rep Urol.; 2020, 12: 383-389, doi: 10.2147/RRU.S267417.

[4]Kuwertz-Bröking E , Gontard A.V, Clinical management of nocturnal enuresis, Pediatr Nephrol; 2018, 33(7):1145-1154, doi: 10.1007/s00467-017-3778-1.

[5]Bakhtiar K, Pournia Y, Ebrahimzadeh F, Farhadi A, Shafizadeh F, Hosseinabadi R, Prevalence of Nocturnal Enuresis and Its Associated Factors in Primary School and Preschool Children of Khorramabad in 2013, Int J Pediatr. ; 2014, doi: 10.1155/2014/120686.

[6] Sarici H, Onur Telli, Berat Cem Ozgur, Arif Demirbas, Senem Ozgur, Mehmet Ali Karagoz, Prevalence of nocturnal enuresis and its influence on quality of life in schoolaged children, Journal of Pediatric Urology; 2016, 12, 3, 159.e1-159.e6.

[7] Fagundes S. N, Adrienne Surri Lebl A.S, Soster L.A, Silva G.J SE, Silvares EF.DM., Koch V.H, Monosymptomatic nocturnal enuresis in pediatric patients: multidisciplinary assessment and effects of therapeutic intervention. Pediatr. Nephrol. ;2017,32(5):843-851.
[8] Haid B, Tekgül S, Primary and Secondary Enuresis: Pathophysiology, Diagnosis, and Treatment, Pediatric urology; 2017, 3, 2-3, 198-206, doi.org/10.1016/j.euf.2017.08.010.

[9]Kiewicz G.P, Nocturnal enuresis in children--how to diagnose, how to treat? Wiad Lek; 2013, 66(1):35-44.

[10] Ferrara P,Amodeo M.E, Sbordone A, Ianniello F, Verrotti A, Petitti T, Ruggiero A, The impact of motivational therapy in the management of enuretic children,Turk $\mathbf{J}$ Urol.; 2018, 44(4): 346-350, doi: 10.5152/tud.2018.50329.

[11]Rincon M.G, Leslie S.W, Lotfollahzadeh S, Nocturnal Enuresis. Stat Pearls, 2020, Available from: https://www.ncbi.nlm.nih.gov/books/NBK54 5181/, accessed on Aug.

[12] Yeung C.K, Sihoe J.D, Sit F.K, Bower W, Sreedhar B, Lau J, Characteristics of primary nocturnal enuresis in adults: an epidemiological study, BJU INTERNATIONAL; 2004，93，341-345, doi:10.1111/j.1464-410X.2004. 04612.x 341. [13]Ali A.M., Prevalence of Enuresis in Sample of Iraqi Children, IRAQI J MED SCI.2012; 10,1.

[14]Saleh A.A, Al-Saffar a.j, Nocturnal Enuresis and its Relation to Child's Behavior in a Sample of Children from Baghdad, Iraq, Iraqi JMS.; 2015,13(1).

[15] Wen J.G, Wang Q.W, Chen Y, Wen J.J, KuiLiu, An Epidemiological Study of Primary Nocturnal Enuresis in Chinese Children and Adolescents, European Urology; 2009, 49, 6, 1107-1113.

[16]Sherah K.M, Elsharief M.W, AbdhBarkat N.A, Jafery A.M, Prevalence of nocturnal enuresis in school-age children in 
Saudi Arabia, IJMDC.; 2019, 3(8): 669-675, doi: 10.24911/IJMDC.51-1547073432.

[17] Awn M.A, Ali N, Al Saqer H, Al Laith D, Al Sayyad A, Prevalence and factors associated with nocturnal enuresis among children attending primary care in Bahrain, $\mathbf{J}$ Bahrain Med Soc.; 2018, 30(1):14-21.

[18] Hassoni R.N., Abdul Ridha B, Nocturnal enuresis in children and its associated factors: an experience from the Child Welfare Teaching Hospital in Baghdad, Iraqi New Medical Journal.; 2017, 3(2).

[19]Gunes A, Gunes G, Acik Y,Akilli A, The epidemiology and factors associated with nocturnal enuresis among boarding and daytime school children in southeast of Turkey: a cross sectional study; 2009, BMC Public Health, 9:357.

[20]Sá C.A, Paiva A.C, Menezes M.C, Oliveira L.F, Gomes C.A, Figueiredo A.A, Increased Risk of Physical Punishment among Enuretic Children with Family History of Enuresis,Journal of UrologyVoiding Dysfunction1; 2016, 195,4, 12271231,doi.org/10.1016/j.juro.2015.11.022 